\title{
Language and Interpersonal Values Education: Teachers' Roles and Perspectives on Students' Language Behaviour Education in Technology- Mediated Communication
}

\author{
AdiSuryani \\ ITS (Institut Teknologi Sepuluh Nopember), Surabaya, Indonesia \\ adisuryani.rahman@gmail.com
}

\begin{abstract}
Language which is intertwined with communication is the central aspect of an interpersonal relationship. It contains the dimensions of values, culture and feeling/emotion which can foster or obstruct and damage a social relationship. Thus, it is vital to insert language/communication attitude education within all contexts of teaching and learning, within everyday natural, authentic environment. Today, many teacher-students interactions are mediated by technology. The technology accelerates, eases or buffers communication between students and teachers. Students do not have to come to see their teachers directly to ask for clarification of an assignment, important deadline or missing information. However, relationship/interaction problem can arise when teachers feel that their students do not communicate politely to them. This study aims to explore how two teachers view and feel about their students' language and communication by using technology as the media, how they perceive the significant need of language/communication attitude education and how they perceive their roles to educate students' language/communication behavior. This study adopted qualitative-case study-phenomenology-interview, and written responses approaches to collect and analyze the data. The data show that the teachers feel that in spite of their students' inappropriate/impolite language, they feel that they should become a role model who can show exemplary behavior in communication and facilitate their students to internalize social interpersonal values and reflect/insert those values in their communication. The teachers feel that technology can conceal students' real language/communication capacity. The data also show that language and communication should be taught, learned and practiced naturally (unconsciously) through daily interaction within an authentic environment. The students should not only be taught to be proficient communicators in expressing their ideas on paper assignments, but more importantly, they should be able to use their language/communication to develop and maintain a social relationship with others. This requires both teachers and students to consider the dimensions of ethics, values, culture and emotion in communication.
\end{abstract}

Keywords: teachers' roles, teachers' perspectives, teachers-students interactions, interpersonal relationship, interpersonal communication, language behavior, language education

\section{INTRODUCTION}

Students' language capacity should not only be reflected in their papers. It should not be assessed through how well they can write or express their ideas through essays or manuscripts, but through direct interaction/communication within their daily communities. This is ecause language is not just a series of meaningful symbols or having intrinsic properties only, but it has external attributes. These attributes relate to social contexts, including values, other people's emotion, attribution, perception, ethical, and cultural dimensions.

Recently, the rapid development of technology has infiltrated into the education sector and affects the nature of the interaction between teachers and students. By using short text messages or what's up facilities, teachers can more effectively manage their classroom. Similarly, students can also benefit from technology-mediated communication with their teachers since they can communicate with their teachers more easily for asking or confirming assignments, scheduling, or catching up with the missed meetings. However, technology can also impede effective communication, especially when teachers feel that their students use impolite language and inappropriate manner. This also may happen when teachers communicate appropriately with their students. This indicates that to establish effective interaction, both interlocutors should be aware of the social or external dimensions of language. It is expected that by considering the social elements of language, the interlocutors will not hurt each other. This also implies that language has social codes which need to be taken into account.

This paper aims to explore several teachers' feeling and thinking on their students' communication capacity which is mediated by technology (mobile phone or smart-phone). It focuses on teachers' responses (roles) and perspectives in developing students' interpersonal values learning through language/communication with their teachers. The aim of the study is formulated into the following research questions:

How are teachers' and perspectives on facilitating their students' interpersonal values learning emerged from their technology-mediated communication/interaction with their students?

What/which interpersonal values teachers expect the students to learn from the students' interaction with them (the teachers)? 


\section{THEORETICAL FRAMEWORK}

Language carries the social and affective dimensions. When a speaker or an individual uses inappropriate language which may offend other people's feeling, it can disturb their social interaction. Language is a mean to express one's emotion and generate other people's particular emotion (Wilce, n.d.). Language can also be used to regulate other people's emotion (Eisenberg, Sadovsky \& Spinrad, 2005). This implies that to develop and maintain a social relationship with others, an individual should be aware of social codes. An individual can be free to choose how they communicate with his/her language, but his/her language is restricted to grammatical and social constraints (Gumperz, 2011). Moreover, Gumperz (2011) argued that grammatical codes determine language approved by certain standards, while social constraints influence social acceptance. As people live in their social environment, they should communicate their intentions, ideas, and emotions to develop themselves as part of a collective group (Iurea, 2015).

Teachers have profound impacts on students' learning. How teachers communicate with their students can affect students' participation in interaction/engagement (Zarrinabadi, 2014). Teachers have the power to control or manage communication in a classroom or with their students outside the classroom. They have the capacity to create a supportive environment to learn, as mentioned by Iurea (2015, p. 367) "...In this predominantly communicative environment, teachers must prove they possess communication skills and, at the same time, they are able to train and develop information skills and communication skills in students as prerequisites of an effective learning a rich social life and high-quality relationship." Teachers' capacity to communicate also stimulate students' safe feeling when they learn (Urea, 2013). Furthermore, Du ă (2015) explored several sources which can impede social relationship between teachers and students, including physical, perceptual, emotional, cultural, language, gender, and interpersonal obstacles.

Today's students tend to be different from the previous generation. In this digital era, people are surrounded by technology which can affect their lifestyle and interaction/communication (Ünal \& Yagci, 2014). Moreover, Ünal and Yagci (2014) mentioned that today's students use most of their time to interact with other people, including with teachers, by using their mobile phones. Technology enables more effective communication between students and teachers, and it is apparent that students like to communicate with their teachers personally through mobile phones (Du ă, 2015). Based on their research in the Turkish context, Ünal and Yagci (2014, p. 3091) stated that when communicating, people may not be conscious that they use inappropriate language. Ünal and Yagci (2014) identify issues among today's young people pertained to technology-mediated communication. They found that "unconscious, inattentive and misuse of language is as common as the use of informal language among the young, which causes degeneration of the language." Furthermore,
Gumperz (2011) also highlighted the importance to socially accepted rules.

\section{RESEARCH METHOD}

The issues are explored by using a qualitative method. This qualitative study is grounded on phenomenological stance. A phenomenological study views lived experiences as sources of finding knowledge, which is obtained by exploring the core of direct experiences as a particular approach to see the world (van Manen, 1990). The data were collected through interviewing and analyzing two teachers at high education levels. The teachers-participants reveal their experience when they communicate/interact with their students by using digital media, conveying what they feel and think about their students' communication/interaction and what they should do as teachers. The collected data are analyzed by using "transcendental approach." This approach is performed by "reducing, displaying data, drawing and verifying conclusions" (Miles \& Huberman, 1994, p. 4, cited in Punch, 2005, p. 197).

\section{DATA PRESENTATION AND DISCUSSION 4.1. Presentation of Some Samples of Data}

The data are classified into two main categories. Data in the first category show that some of the students do not use proper language and way of communication to interact with the teachers through SMS or WhatsApp. Some of their behaviors are hiding behind their technology to express their feelings, breaking social and technical communication rules prescribed by teachers and agreed by students, and not being careful with the language they use to send messages to their teachers. However, there are also some students who are careful and show polite and respectful manner to communicate with their teachers.

In spite of diverse students' language/communication behavior, the teachers are aware that as teachers, they should not only teach their subjects, but also are obliged to build/develop students' good characters through every day/daily practices of interaction, including showing how to use language and communicate with others (older people) properly. The data show that the teachers perform self and social emotion regulation/management, facilitate students' language/communication learning, remind, tolerate students' misbehavior, establish closer communication/interaction, trace the causes and understand students' communication attitude, show/become role models, and respond students' communication using polite manner. Below is an extract from the first category, on how teachers view their roles as teachers.

"...teachers should be able to be an educator, not only teaching the content subject, but they should take care, facilitate, and become mother/father for their students. For example, when we write the name of a person, we should use a capital letter for the initial, we should perceive what our students do or their weakness as a regular thing, and it is very human. That is my thinking paradigm which affects my interaction behavior with my students. Even though, 
as a normal person, I also feel angry to my students because of their ways of communicating. I try to understand in which area they are nurtured. I do not blame these students or conclude that they these students are not good students, but I try to explore their childhood environment in which he/she receives everyday education" (Teacher-1)

The data on the teachers' roles in communicating with their students show that they should function not only as teachers, but also as fathers/mothers, friends, reminders, and controllers. They believe that what they should control is not only their students' communication/language behavior but also their self-regulation or emotional control. Thus, teachers should develop the capacity to be participative role models in which they can show and guide their students to acquire demanded/favorable language/communication behavior. Through their interaction with their students, they attempt to insert and embed interpersonal values. Below are several extracts from data samples of what interpersonal values they expect their students to learn.

"I think, students should use appropriate manner and proper language to communicate with their teachers. How they interact, what language they use, what style of communication they use should be appropriate. Communication does not only have content dimension, but also relationship aspect. As the next generation, students should concern relationship dimension teachers should shape, grow and develop students' positiveproductive communication skill since it is very vital for building a relationship. It is needed for cooperation in a team, building and maintaining brotherhood. If we have good communication, we are going to feel happy. We have a rich social relationship. That is the social capital which should be searched and owned by all young generation, our students" (Teacher-1)

"...I ever remind a student, but he/she cannot accept it, he/she send me messages...I think that this student is very silent in the class, but he/she is very aggressive in the virtual world. I ask him/her, why in class, you never ask me what you feel wrong? You become very upset when you know your presentation mark and get angry at me through SMS. Even there are some students do not complain directly, but just through their friends, he/she asks his/her friends to ask to clarify his/her mark to me. I say to this student, "ask your friend to see me directly. The point is communication relates to character, students' courage to ask and talk directly." (Teacher-2)

The data show that teacher-1 emphasizes social dimension in communication. He believes that language has relationship elements which can destroy or increase students' relationship with others. Through their interaction, Teacher-2 is aware that his students should not use digital/technology media to hide their selves from direct social communication. He emphasizes the need to be responsible for their language/communication attitude instead of using technology as their language/communication mask.

\subsection{Discussion}

This section provides a detailed discussion on abstraction-conceptualization of the data and links to data/practices to theories. The data show that the teachers actively insert interpersonal values education when they interact with their students. They do not teach those values as concepts, but they implement the values into daily responses through interaction with their students. This indicates that social interaction between teachers and students can be effective media for teachers to educate students how to use their language or communicate in their daily life. Both the teachers and students are engaged in action learning and experiential learning. "Learning about" is different from learning how in which from "learning how," teachers and students can get lessons from experiences through contemplating, modeling and doing as responses to daily interaction (Sessa \& London, 2006, p. 19). This also indicates the needs to learn from the unconscious and natural situation and engage in situated learning.

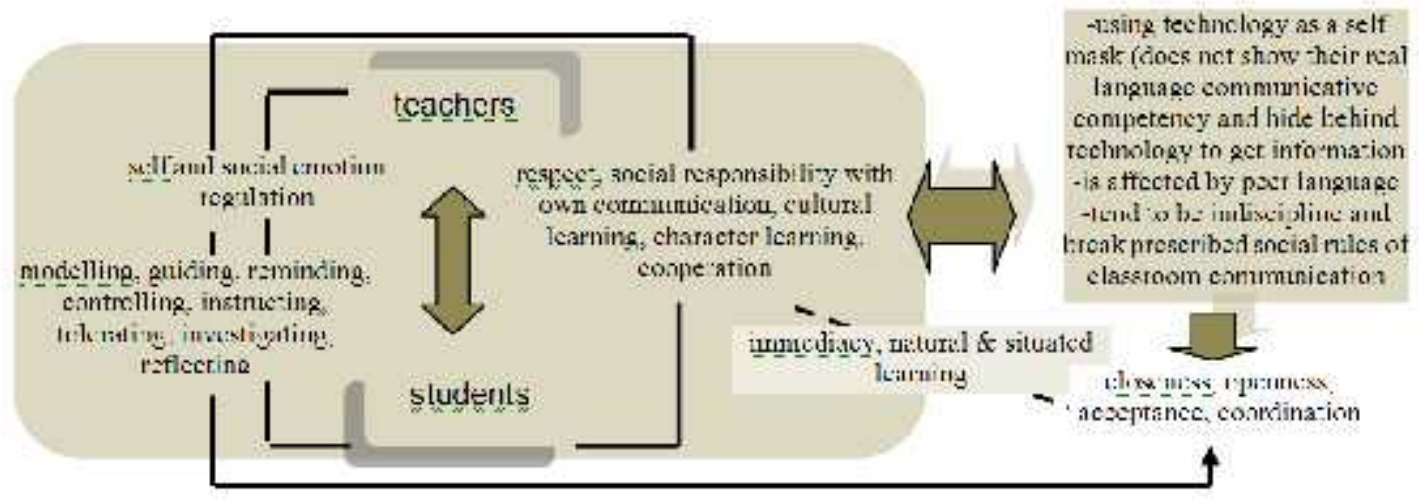

Figure 1. Teachers' roles and interpersonal values education 
Technology for communication creates an

To educate their students, teachers should not only be proficient in their subject matter, but also occupy roles as values educators. They should guide, mentor, model, instruct/order, investigate, remind, tolerate, reflect and regulate their students' language/communication behavior. However, the teachers indicate that these educating processes should be started from controlling/regulating their self-emotion. Their students' language/communication behaviors frequently stimulate their anger; for example, they use peer language, westernized language/way of communication, do not show respect, violate prescribed/agreed classroom communication rules, and show academic neglect and indiscipline. Thus, it is expected that the teachers can control their emotion. Teaching is a social process which means that how students behave can generate teachers' emotion and vice versa. Emotion from interaction frequently arises when other people do not fulfill what other people expect (Golombek \& Doran, 2014, p. 102) In spite of their anger, the data show that the teachers attempt to reduce their anger by exploring the reasons of students' language/communication behavior. They try to understand what happens to their students. This action may reinforce teachers' learning about their students' needs, issues, and social contexts of their classroom. To increase their professional competencies, teachers should develop the capacity to manage their emotion and view it as aids for learning (Golombek \& Doran, 2014). They also remind their students to change their behavior and show which behavior is acceptable/favorable and which one they should avoid. This indicates that the teachers perform not only self-emotion management, but also social regulation. The teachers do not only manage their emotion, but they remind their students to adopt desired ways of communication. Different from selfemotion regulation which emphasizes the role of self-own in controlling/suppressing own emotion, social emotion regulation involves others to regulate emotion (Reeck, Ames \& Ochsner, 2016). Teachers attempt to understand their students' behavior by exploring what stimulates their behavior: is it because of culture, family background or friends' influence, but still, they remind the students to change/adapt their language to different situation/contexts. The data from teacher2 show that the process of understanding occurs when students' stimulates closeness and openness in social relationship between teacher (teacher-2) and the students. Teachers' capacity to manage emotion and build open communication can lead to closeness and immediacy through social relationships. This can also affect students' learning and understanding on teachers' assessment, feedback, comment, and advice. Through this immediacy, it is expected that teachers can create and develop conducive and supportive classroom life through interaction/communication. Teachers have the capacity/authority to determine how interaction/communication with their students flow (Yusof \& Halim, 2014). As educators, it is expected that teachers should play their roles within their social systems since deviating behavior may have an impact on social interaction, social functioning and decrease performance (Ziller, 1973). opportunity for teachers to insert interpersonal values through their interaction. The data show that there are several relational values they expect their students to learn. Those are respect, social responsibility for their behavior instead of hiding behind technology, management of self-emotion, cooperation, social concern/attention, cultural learning and comforting response. The teachers are also aware that language/communication education also cannot be separated from character education since language/communication can be the reflection of the students' characters. However, they are also alert that how their students communicate through technology may not reflect their actual characters/language communicative skills since technology allows them to check and modify their language. Figure 1 (teachers' roles and interpersonal values education) represents the brief relationship between teachers' action in embedding interpersonal values and issues they encounter during their interaction with their students using technology.

\section{CONCLUSION}

Teachers play substantial roles in embedding values within students' life. The teachers model, guide, instruct, remind, and control/prescribe the students' language/communication behavior. However, to be able to function as educators, teachers should be able to control their emotion. The infiltration of technology in education allows effective interaction between teachers and students. It can provide a natural learning environment which allows teachers to insert interpersonal values education through natural and daily interaction.

\section{REFERENCES}

Eisenberg, N., Sadovsky, A., \& Spinrad, T. L. (2005). Associations of emotion-related regulation with language skills, emotion knowledge, and academic outcomes. New directions for child and adolescent development, 2005(109), 109-118.

Du ă, N. (2015). From theory to practice: the barriers to efficient communication in teacher-student relationship. Procedia-Social and Behavioral Sciences, 187, 625-630.

Golombek, P. \& Doran, M. (2014). Unifying cognition, emotion, and activity in language teacher professional development. Teaching and Teacher Education, 39, 102111.

Gumperz. J., J. (2011). Linguistic and social interaction in two communities. American Anthropologist, 66 (6), 137-153.

Iurea, C. (2015). Classroom environment between stimulation and discouragement. Teacher's contribution to creating new socio-effective environment favoring the teacherstudent communication. Procedia-Social and Behavioral Sciences, 203, 367-373.

Punch, K. F. (2005). Introduction to social research. Quantitative and qualitative approaches. London: SAGE Publications Ltd. 
Reeck, C., Ames, D., R. \& Ochsner, K., N. (2016). The social regulation of emotion: An integrative, cross-disciplinary model. Trends in Cognitive Sciences, 20 (1), 47-63.

Sessa, V. I., \& London, M. (2006). Continuous learning in organizations: Individual, group and organizational perspectives. New Jersey: Lawrence Erlbaum Associates, Inc.

Ünal, M., \& Yagci, M. (2014). Self-evaluation of students' language in the frame of information and communication technologies. Procedia-Social and Behavioral Sciences, 116, 3090-3095.

Urea, R. (2013). The impact of teachers' communication styles on pupils' self-safety throughout the learning process. Procedia-Social and Behavioral Sciences, 93, 164-168.

Van Manen, M. (1990). Researching lived experience. Human science for an action sensitive pedagogy. Canada: State University of New York Press.

Wilce, J. M. (n.d.). Language and emotion. Retrieved on July 6, 2016, from www.googlescholar.com.

Yusof, F. M., \& Halim, H. (2014). Understanding teacher communication skills. Procedia-Social and Behavioral Sciences, 155, 471-476.

Zarrinabadi, N. (2014). Communicating in a second language: Investigating the effect of teacher on learners' willingness to communicate. System, 42, 288-295.

Ziller, R. C. (1973).The social self. New York: Pergamon Press, Inc. 